\title{
Estratégia de luta na superação da exclusão escolar: o papel dos técnicos sociais
}

\section{Strategies in the struggle to overcome educational exclusion: the role of social workers}

\author{
Sabrina Zientarski de Bragança* \\ Clarice Zientarski* \\ Sueli Menezes Pereira**
}

\begin{abstract}
Resumo: Este artigo trata das possibilidades de rompimento de práticas de exclusão escolar através de ações realizadas pelos técnicos sociais (ATES), que têm como proposta a educação popular emancipatória, representando um movimento contrário à hegemonia dominante. Consiste em estudo de caso com abordagem qualitativa (TRIVINÕS, 1987), apresentando resultados parciais da pesquisa desenvolvida com assentados da reforma agrária nos municípios de São Gabriel e Santa Margarida do Sul (RS). A ação de assistência realizada pelos técnicos de diversas áreas é entendida como uma política pública, conquistada através de pautas travadas com o Ministério da Agricultura e setores das áreas de Assentamento do INCRA, constituindo um movimento social relacionado diretamente com a educação. Conclui-se que, apesar da pouca atenção do Estado Capitalista, esses movimentos constituem-se em ações educativas de caráter emancipatório para os sujeitos sociais envolvidos.
\end{abstract}

Palavras-chave: Assentamentos de Reforma Agrária. Educação. Técnicos Sociais.

\begin{abstract}
This article deals with the possibilities of disruption of exclusive practices in education through the actions performed by the social workers (ATES), who propose an emancipative popular education, which represents a contrary movement to the dominant hegemony. It consists of a case study with a qualitative approach (TRIVINÕS, 1987), presenting partial results of the research developed with agrarian reform settlers in the cities of São Gabriel and Santa Margarida dos Sul (State of Rio Grande do Sul). The assistance provided by social workers of several different fields is understood as a governmental policy, achieved through negotiations with the Ministry of Agriculture and with sectors of the settlement areas defined by the Instituto Nacional de Colonização e Reforma Agrária (National Institute for Colonization and Agrarian Reform - INCRA), being, therefore, a social movement directed related to the education. It is possible to conclude that, although receiving little attention of the capitalist State, these movements represent educational actions of an emancipative nature for the involved social actors.
\end{abstract}

Keywords: Agrarian reform settlements. Education. Social workers.

\footnotetext{
* Mestranda em Educação da Universidade Federal de Santa Maria. E-mail: <sabrina_educaomst@yahoo.com.br> ** Doutoranda em Educação pela Universidade Federal de Santa Maria. E-mail: <claricezientarski@yahoo.com.br>

**** Professora da Universidade Federal de Santa Maria - UFSM. E-mail: <sueli@ceufsm.br>
} 


\section{Introdução}

Este texto tem como proposta analisar as atividades desenvolvidas pelos técnicos sociais da COPTEC/RS (Cooperativa de Prestação de Serviços Técnicos Ltda do Rio Grande do Sul), na condição de trabalhadores frente às ações ou/e omissões do Estado com relação aos assentamentos de Reforma Agrária. Os referidos técnicos ${ }^{1}$ têm formação em diferentes áreas de atuação profissional, mas, neste trabalho, dar-se-á ênfase aos técnicos licenciados, considerando sua atuação como iniciativas populares que possibilitam a transformação da realidade concreta em uma perspectiva crítica, tal qual a dialética oprimido $x$ opressor, explicitada por Paulo Freire em suas obras. Analisa, assim, as ações realizadas e as dificuldades enfrentadas em diferentes espaços públicos, sendo os assentamentos de São Gabriel e Santa Margarida do Sul, no Rio Grande do Sul, Brasil o lócus de atuação destes trabalhadores no exercício de sua função. Ressalta-se que os técnicos estão ligados ao serviço de Assessoria Técnica, Social e Ambiental à Reforma Agrária (ATES), criado pelo Instituto Nacional de Colonização e Reforma Agrária (INCRA) em 2004. No caso da COPTEC/RS, trata-se de uma Sociedade Cooperativa de Prestação de Serviços Técnicos em áreas de Reforma Agrária, fundada em 1996, voltada ao desenvolvimento sustentável dos assentamentos de reforma agrária no Estado do Rio Grande do Sul.

Por sermos integrantes e pesquisadores dos movimentos sociais de caráter popular, este estudo de caso revela a preocupação em entender por que o Estado se omite em relação à educação e, ao mesmo tempo, inibe as ações educativas realizadas pelos sujeitos sociais envolvidos em práticas educativas conscientes. Nesta perspectiva, designa-se como movimento social aquele cuja condução "o trabalhador toma para si" (CASTORIADIS, 1983, p. 36) e representa uma possibilidade de organização, articulação e muitas vezes de sua própria sobrevivência ou da instituição a que pertence. Isso indica a premissa de que todo movimento social é formado por agrupamentos humanos inseridos na sociedade e que está "articulado a um conjunto de crenças e representações e são elas que dão suporte às suas estratégias e desenham seus projetos político-ideológicos" (GOHN, 2000, p. 235).

Paulo Freire afirma que a "realidade social objetiva [...] não existe por acaso, mas como produto da ação dos homens, também não se transforma por acaso". Vai além e refere que, "se os homens são os produtores desta realidade e, se esta, na invasão da práxis, se volta contra eles e os condiciona, transformar a realidade opressora é tarefa histórica, é tarefa dos homens" (FREIRE, 1985, p. 39). Trazendo o pensamento de Marx (2011) quanto à relação dialética

\footnotetext{
${ }^{1}$ Em Santa Margarida e São Gabriel, no Rio Grande do Sul, Brasil, além dos técnicos formados em licenciaturas, atuam ainda agrônomo, economista, veterinário e técnicos agrícolas, totalizando 11 profissionais.
} 
subjetividade-objetividade, o pensador explica o processo de transformação no sentido amplo de teoria e prática, de conscientizar para transformar, pois a opressão é uma forma danosa e sinistra de violência.

Nesta ótica, os movimentos sociais em geral, especialmente os ligados à educação, têm sido uma resposta para os problemas que se apresentam na sociedade, por estarem carregados de uma racionalidade ligada ao papel político que a educação desempenha. Isto se compreende, no caso em estudo, por que os sujeitos sociais, mesmo tendo suas ações limitadas em grande parte, por conta do conjunto de situações impostas pelos grupos dominantes, se posicionam como sujeitos e conduzem suas ações em benefício dos grupos sociais aos quais estão ligados. Por outro lado, apesar do fato de os técnicos sociais não concordarem com muitas decisões de caráter estatal, no exercício de sua função a serviço da sociedade, acabam atendendo também ao interesse do Estado².

Realizar seu trabalho de forma consciente e responsável implica a recusa em aceitar situações nas quais "não cheguem a localizar o opressor concretamente, como também, movimentos que não tenham 'consciência para si”'. Neste caso, não assumem atitudes fatalistas diante da situação concreta de opressão em que se encontram (FREIRE, 1967). Esses posicionamentos de reação à ordem imposta, portanto, são as ações que, neste estudo, merecem um enfoque especial.

No que diz respeito à evolução das relações Estado/sociedade/educação, durante muito tempo e mesmo agora, no século XXI, o centro da ação estatal continua sendo o de garantir as bases de sustentação do modelo capitalista. Isso significa o fortalecimento da relação social básica, ou seja, de opressão e estrangulamento do trabalhador em benefício do capital. A relação da sociedade com o Estado se dá no limite dos conflitos e do confronto de interesses das suas classes, seus grupos e os compromissos assumidos com eles. Se há evidência de que a atuação do Estado deixa a desejar quanto aos grupos menos favorecidos na sociedade, também fica evidente que as classes e grupos melhor posicionados (hegemônicos) orientam a ação estatal. Isto é o que pode ser observado nos assentamentos em São Gabriel e Santa Margarida do Sul à medida que o poder público se omite e, ao mesmo tempo, não permite que os sujeitos sociais comprometidos com a transformação social assumam o comando das ações na área da educação, da cultura e na forma de organização social em busca de melhores condições de vida.

As famílias camponesas que vivem no território conquistado desenvolvem seu trabalho e buscam, por meio do comprometimento com a vida saudável, o crescimento dos municípios, respeitando o meio ambiente e garantindo a

\footnotetext{
${ }^{2}$ Os técnicos, embora façam parte de uma cooperativa, ao prestarem serviço de extensão rural, contribuem com seu trabalho para os propósitos do Estado, o qual é o financiador e também uma espécie de regulador deste trabalho.
} 
sua sobrevivência econômica, cultural e social, fundamentando sua produção na unidade familiar. No entanto, esta situação tem sido prejudicada pelo Estado que não tem se responsabilizado pela manutenção dos incentivos de modo a ampliar nem melhorar a produção ${ }^{3}$, visto que o Estado se mostra cada vez mais comprometido com o agronegócio, como se pode observar, por exemplo, na afirmação feita pelo Ministro da Fazenda Guido Mantega, ao assegurar que os recursos serviriam para financiar principalmente frigoríficos, setor de suinocultura, aves e carne bovina (AGÊENCIA BRASIL, 2009).

De outro lado, a agricultura familiar camponesa é defendida pelos organismos internacionais, entre eles o Fundo das Nações Unidas para a Agricultura (FAO), considerando-se o modelo de uma agricultura sustentável. Além da FAO, organizações nacionais, como a Confederação Nacional dos Trabalhadores/as da Agricultura (CONTAG) e as Organizações NãoGovernamentais (ONGs), apresentam-na como referencial de produção agrícola com base na unidade familiar. Importante ressaltar, neste aspecto, a afirmação de Medeiros (1999), quando sublinha que

o reconhecimento do 'agricultor familiar' como ator social relevante não pode ser entendido sem considerar, de um lado, as mobilizações dessa categoria, em especial através dos 'Gritos' e, de outro, as disputas em torno de quem deveria ser o público preferencial para as ações governamentais. (MEDEIROS, 1999, p. 19).

Nessa ótica, à medida que as reivindicações dos agricultores familiares foram colocadas em pauta, nas discussões com os Governos e sob a pressão dos movimentos sociais, a agricultura familiar passou a ser vista como um modo de organização da produção que se adapta às mudanças econômicas e que resiste às diversas estruturas de mercado e aos processos de desenvolvimento (DIAS, 2004).

É exatamente no que diz respeito à produção realizada no âmbito familiar que o trabalho dos técnicos é fundamental, já que contribui com orientações e suporte, entendendo-se que é impossível em uma pequena unidade produtiva obter retorno econômico e condições de sustentabilidade no sistema capitalista, especialmente no modelo de monocultura. De acordo com o INCRA:

O Programa de Assessoria Técnica, Social e Ambiental à Reforma Agrária (ATES) foi criado em 2003 com o objetivo de assessorar técnica, social e ambientalmente as famílias assentadas nos Projetos de Assentamento (PAs) da Reforma Agrária, criados ou reconhecidos pelo INCRA. A ideia é tornar os

\footnotetext{
${ }^{3}$ Maiores informações sobre esta questão podem ser obtidas na página da Secretaria do Planejamento, Gestão e Participação Cidadã do Rio Grande do Sul. Lá se obtêm os dados de que, em São Gabriel, no período de 2004-2006, houve uma safra média de 10.000-100.000 toneladas de ambos os grãos, sendo a região da campanha a responsável por 9,95\% da produção gaúcha. RIO GRANDE DO SUL, Mapa Socioeconômico. Disponível em: < http://www.seplag.rs.gov.br/atlas/default.asp>. Acesso em: 06 jun. 2011.
} 
PAs em unidades de produção estruturadas, com segurança alimentar garantida, inseridos na dinâmica do desenvolvimento municipal, regional e territorial, de forma ambientalmente sustentável. Uma das premissas do Programa é aliar o saber tradicional dos assentados aos conhecimentos científicos dos técnicos. (INCRA, 2004, s. p.).

Neste contexto, os técnicos trabalham com a problemática da atual estrutura agrícola que está centrada na produção agrícola convencional (dependente de agrotóxicos e insumos industriais) e que necessita de grandes extensões de terra. Isto se deve ao fato de que ela visa às exportações, ou seja, à manutenção da exploração da terra e aos bens com o propósito de manter e sustentar o modelo econômico vigente.

Depois de uma análise técnica da realidade, os profissionais da ATES continuam seu trabalho apresentando alternativas viáveis para a diversificação da produção, bem como estimulando atitudes que levam ao trabalho coletivo e cooperativo nas famílias e entre elas. Nesta sequência de ações, os trabalhadores técnicos enfrentam muitas dificuldades, pois acabam ampliando e acumulando funções, pois assumem aquelas que seriam da competência do poder público.

Essas questões ficam evidentes quando se constata que o Estado não faz a parte que lhe cabe no processo de desenvolvimento da sociedade. Isto se evidencia nas estruturas dos assentamentos pela falta de escolas, de postos de saúde, de segurança pública, bem como pelas dificuldades de acesso e operacionalização de créditos agrícolas, pela falta de assistência social básica, como, por exemplo, a construção de redes de abastecimento de água e esgotos, dentre muitos outros direitos que não estão sendo atendidos.

Neste panorama, a ação dos técnicos sociais é essencial no sentido de minimizar os problemas. Dedicam-se ao desenvolvimento de práticas educativas de caráter popular à medida que realizam pesquisas sobre a realidade educacional presente e empenham-se na busca de soluções para as dificuldades levantadas. Também trabalham com as famílias visando orientá-las em relação às questões de saúde, conscientização sobre seus direitos, realizações de palestras, debates, oficinas e na divulgação de informações e problematização de temáticas que envolvem os camponeses assentados no Rio Grande do Sul.

Os técnicos fundamentam sua ação no entendimento de Arroyo e Fernandes (2000) de que o Campo é "lugar de vida, onde as pessoas podem morar, trabalhar, estudar com dignidade de quem tem o seu lugar e a sua identidade cultural". Desta forma, defendem que o campo não é só lugar da "produção agropecuária e agroindustrial, do latifúndio, de grilagem de terras, portanto, o campo é lugar de vida e, sobretudo, de educação" (ARROYO; FERNANDES, 2000, p. 92). 
Assim, o trabalho realizado pelos técnicos assume uma função social educativa de denúncia, de orientação à produção, valorização da cultura local, de conscientização da necessidade de desenvolver a produção sustentável e criação de espaços educativos que atendam às necessidades do povo camponês que vive neste local e que se percebe excluído das políticas sociais.

\section{O Estado como representante da classe hegemônica}

O Estado, para Gramsci (1978, p. 36), representa a hegemonia garantida pela couraça da coerção, portanto, "sociedade política + sociedade civil". Nesta perspectiva, o autor afirma ainda que o Estado é um educador no sentido de que tende a criar um novo tipo ou nível de civilização. Ele opera segundo um plano, impulsiona, incita, solicita, pune. Essas ações levam a uma revolução passiva, ou seja, a uma constante reorganização do poder do Estado no sentido de preservar sua hegemonia com a exclusão das massas das instituições econômicas e políticas.

Estabelecendo a relação entre sociedade política e sociedade civil, Gramsci supera o conceito de Estado como sociedade política quando compreendido isoladamente. Para esse pensador, sociedade política representa um conjunto de mecanismos através do qual a classe dominante detém o monopólio legal da repressão e da violência. Desta forma, identifica-se com os aparelhos de coerção sob controle dos grupos burocráticos ligados às forças armadas, policiais e à aplicação das leis no sentido de adequar as massas às relações de produção.

A sociedade civil, por sua vez, designa o conjunto das instituições responsáveis pela elaboração e/ou difusão de valores simbólicos e de ideologias, compreendendo o sistema escolar, os partidos políticos, as corporações profissionais, os sindicatos, os meios de comunicação, as instituições de caráter científico e cultural, entre outros.

A concepção de Estado em Gramsci também se confirma com a obra de Marx "O Dezoito Brumário", a qual esclarece que, na história, a consciência social tem como seu estruturante e dialético fundamental o ser social. No caso do capitalismo, configura-se no seu modo de produção e nas principais classes sociais em luta: a burguesia e o proletariado. Os fatos particulares, no entanto, são apenas a aparência de relações essenciais e mais profundas, só percebida na relação realidade abstrata/ concreta.

Quando Marx (1974) tratou sobre a França de 1848-1852, buscou entender como uma nação de trinta e seis milhões de habitantes pôde ser surpreendida e chegou a se entregar sem resistência ao cativeiro por cavalheiros da indústria (KONRAD, 2011). Neste sentido, ele faz com que se questione sobre a força 
do Estado como sociedade política. Esta preocupação é atual para perceber a realidade social, o que nos faz recorrer a Marx para compreender este momento histórico.

Com a leitura das obras de Marx, pode-se perceber por que o proletariado recuou naquele momento histórico (1848-1852) e de que forma se dão as restrições das liberdades políticas, a questão do poder e as contradições entre os próprios grupos dominantes. No caso do Rio Grande do Sul, ajuda a entender a dissimulação da luta de classes, por exemplo, quando se apresentam as ações realizadas pelos movimentos sociais como vandalismo, destacando-se o papel da imprensa na defesa dos dominantes, especialmente na divulgação das suas ações como nobres, a luta pela manutenção do poder político e social pelo capital, dos governantes e de parte da sociedade civil.

No caso dos municípios de Santa Margarida e São Gabriel, as ideias de Marx (1974) ajudam a compreender o processo de trabalho no capitalismo. As relações de trabalho neste sistema são de exploração de uma classe sobre a outra; além disso, o objeto de trabalho, os meios e os instrumentos utilizados na produção da economia local estão a serviço do capital. A maioria das terras economicamente produtivas da região está a serviço do agronegócio, pois mais de 65\% delas produzem arroz e soja, principalmente para a exportação.

Há uma intensa utilização de produtos químicos e de máquinas agrícolas, o que, ao invés de facilitar o trabalho dos camponeses, faz com que se tornem dependentes do capital internacional e consumidores permanentes desses produtos. Isto se torna evidente à medida que ocorre um desequilíbrio no ecossiste$\mathrm{ma}$, tais como os longos períodos de seca, as chuvas intensas, a desertificação. $\mathrm{O}$ desgaste da terra e dos recursos naturais faz com que recorram aos mecanismos do capital e do Estado, buscando financiamentos, empréstimos a juros altíssimos e comprometimento total dos seus rendimentos, o que os faz reféns da economia capitalista de mercado.

Essas são, portanto, questões que Marx ajuda a entender, uma vez que, ainda hoje, o capitalismo, em sua fase imperialista reafirmada com a globalização econômica, faz com que as classes sociais estejam permanentemente em contradição e luta, seja para manter as relações sociais, econômicas, culturais, políticas e ideológicas de um modo de produção, seja para mudá-las. A relação do mercado e do capital são apoiados e sustentados pelos governos, enquanto que os movimentos sociais e suas lutas são contra os governos e contra o capitalismo, apesar de estarem submissos às suas regras.

O Estado, ao mesmo tempo em que anuncia práticas democráticas, utiliza-se de políticas de cunho liberal ou neoliberal, ao transferir para a iniciativa privada não lucrativa os serviços sociais, científicos, culturais e educacionais 
determinados no Plano de Reforma do Estado. Essa democracia participativa levou os movimentos sociais a uma postura propositiva diante do Estado, especialmente na luta pela educação do campo, os quais, entretanto, são reprimidos pelo mesmo aparato de sustentação do Estado. Apontam-se, como exemplo, o fechamento da Escola Itinerante do MST (Movimento dos Trabalhadores Rurais Sem Terra), a falta de interesse do Governo de São Gabriel para a efetivação do Projeto da Escola Polo ${ }^{4}$, dentre outras ações.

[...] As Escolas Itinerantes beneficiavam 600 crianças e foram fechadas numa decisão autoritária da Governadora do Estado e do Ministério Público sem consulta aos pais, educadores e alunos. No ano passado, o Governo do Estado já havia atrasado em nove meses os salários dos educadores e não realizava a entrega de material didático. O Governo do Estado determinou a transferência das crianças acampadas para escolas nos municípios onde estão os acampamentos. Mas alguns prefeitos já se manifestaram contra a decisão, alegando não possuírem recursos para receberem as crianças (JORNAL MST, 02 mar. 2009).

Assim como o trabalho realizado pelo MST, de luta pela escola itinerante, de denúncia e de conscientização da necessidade de desenvolver a produção sustentável, insere-se o trabalho dos técnicos sociais. O trabalho feito pelos técnicos assume ainda, nesta perspectiva, a função de orientar a produção, valorizar a cultura local e criar espaços educativos que atendam às necessidades do povo camponês que vive neste local.

\section{O trabalho humano: sua importância e a sua apropriação pelo sistema do capital}

Na elaboração do mundo objetivo é que o homem se confirma, em primeiro lugar e efetivamente, como ser genérico. Esta produção é a sua vida genérica operativa. Através dela a natureza aparece como sua obra e a sua afetividade. O objeto do trabalho é, portanto, a objetivação da vida genérica do homem; quando o homem se duplica não apenas na consciência, intelectualmente, mas operativa, efetivamente, contemplando-se, por isso, a si mesmo num mundo criado por ele. (MARX, 2011, p. 85).

As frases de Marx em epígrafe fazem perceber que o trabalho que transforma é uma atividade inerente aos homens: uma atividade humana. $\mathrm{O}$ trabalho é a fonte da essência humana e, através dele, o homem se diferencia dos demais seres. Marx (2011) toma como princípio que o trabalho é a atividade vital do

\footnotetext{
${ }^{4}$ A Escola Polo é um projeto de parceria entre o Ministério da Educação e Cultura e o Ministério do Desenvolvimento Agrário em que fica estabelecida a construção de escolas em áreas de assentamento onde se apresentam demandas com relação ao número de alunos (densidade demográfica) e especificidades geográficas e socioeconômicas. Estas escolas atendem a um número significativo de assentamentos.
} 
homem, ou seja, a base que fundamenta a realização do seu gênero; compreende, portanto, que o homem expressa seu verdadeiro caráter genérico enquanto trabalhador, na produção e reprodução de sua vida material.

Em seus escritos, permite a compreensão de que, da ação do homem sobre o mundo objetivo e sobre a natureza, emerge sua obra e realidade, desde que o homem aja consciente e voluntariamente e com base num plano predeterminado; assim, ele se diferencia dos animais.

Ao imprimir tais mudanças na natureza externa, o homem modifica sua própria natureza. Esta relação é histórica, processual, guarda particularidades que se situam no tempo e no espaço. A cada forma de sociedade corresponde, portanto, uma determinada forma de produção, com uma organização e divisão particular do trabalho e a instituição de meios de produção adequados a finalidades específicas. Tais condições são revolucionadas sempre que se constituem em entraves às forças produtivas materiais da sociedade.

Marx aponta:

[...] na produção social da sua existência, os homens estabelecem relações determinadas, necessárias, independentes da sua vontade, relações de produção que correspondem a um determinado grau de desenvolvimento das forças produtivas materiais. O conjunto destas relações de produção constitui a estrutura econômica da sociedade, a base concreta sobre a qual se eleva uma superestrutura jurídica e política e a qual correspondem determinadas formas de consciência social. O modo de produção da vida material condiciona o desenvolvimento da vida social, política e intelectual em geral. Não é a consciência dos homens que determina o seu ser; é o seu ser social que, inversamente, determina sua consciência. Em certo estágio de desenvolvimento, as forças produtivas materiais da sociedade entram em contradição com as relações de produção existentes ou, o que é a sua expressão jurídica, com as relações de propriedade no seio das quais se tinham movido até então. De formas de desenvolvimento das forças produtivas, estas relações transformam-se no seu entrave. Surge então uma época de revolução social (MARX, 2011, p. 24-25).

É da maior significação a esse respeito ressaltar o caráter consciente e livre da atividade humana direcionada ao trabalho como criador de valor-de-uso. Essa característica é que diferencia a espécie humana da dos outros animais. $\mathrm{O}$ produto final do trabalho, o esforço que é transformado em coisa física, constitui a objetivação da vida genérica do homem. O homem criador percebe sua própria imagem no mundo por ele criado, ele se identifica com a sua produção, pois é o resultado do desejo, da vontade da sua consciência livre. (MARX, 2011).

O trabalho, portanto, tem uma importância tão grande que, uma vez compreendida na sua historicidade material e dialética, permite alcançar uma 
definição de homem como aquele ente que, para ser, necessita produzir os seus próprios meios de subsistência material e simbólica. Assim como assinalam Marx e Engels:

O primeiro pressuposto de toda a história humana é, naturalmente, a existência de indivíduos humanos vivos. [...] O primeiro ato histórico destes indivíduos, através do qual eles se diferenciam dos animais, não é o fato de eles pensarem, mas sim de eles começarem a produzir seus víveres (Lebensmittel). (MARX; ENGELS, 2007, p. 41-42).

O trabalho é um processo de que participam igualmente o homem e a natureza, indicando que existe uma relação de igualdade entre o homem e a natureza, portanto, não há dominador. "O trabalhador nada pode criar sem a natureza, sem o mundo exterior sensível” (MARX, 2011, p. 202), em que se constata com Marx que, no decorrer do processo de trabalho, o homem transforma a natureza, transformando-se também. Lessa (2007, p. 142) caracteriza a reprodução social desta forma:

Ao contrário da reprodução biológica, a reprodução social é um processo fundado pelo trabalho, um tipo de atividade no qual o indivíduo humano primeiro elabora na consciência (como ideia, como ideação) para depois transformar a natureza naquilo que necessita. Tal interação com a natureza é sempre, como veremos, mediada pela consciência e pelas relações sociais; estas comparecem no mundo dos homens com funções que possibilitam um tipo de transformação da matéria natural completamente diferente daquela operada pelos animais e plantas [...] É esse novo tipo de transformação da natureza que, para Marx e Lukács funda a diferenciação do homem com a natureza, funda a evolução humana. O trabalho é, pois, a categoria fundante do mundo dos homens porque, em primeiro lugar, atende à necessidade primeira de toda sociabilidade: a produção dos meios de produção e de subsistência sem os quais nenhuma vida social seria possível. Em segundo lugar, porque o faz de tal modo que já apresenta, desde o seu primeiro momento, aquela que será a determinação ontológica decisiva do ser social, qual seja, a de que, ao transformar o mundo natural, os seres humanos também transformam a sua própria natureza, o que resulta na criação incessante de novas possibilidades e necessidades históricas, tanto sociais como individuais, tanto objetivas quanto subjetivas.

Essa afirmação de Lessa torna-se fundamental quando se analisa o trabalho realizado pelos técnicos sociais da COPTEC e o trabalho realizado pelos governantes, no caso de Santa Margarida do Sul e São Gabriel, à medida que se pensa em termos de representação social. O que se constata é que, no caso dos técnicos, eles atendem aos interesses dos grupos que representam - os trabalhadores camponeses - ao passo que os governantes atendem aos interesses dos grupos dominantes. 
Como já foi salientado neste texto, o homem é capaz de transformar a natureza através do trabalho. Esta é uma relação biológica, como assinala Lessa (2007), e toda a sociedade tem sua existência hipotecada à natureza. O que varia historicamente é a modalidade de organização dos homens para explorarem a natureza. No espaço que se analisa (Santa Margarida e São Gabriel), a reprodução da sociedade continua dependendo da natureza. Há, no entanto, uma grande diferença no que diz respeito ao trabalho que é a sua subsunção ao capital. Neste aspecto, estabelece-se o antagonismo: os técnicos em seu trabalho orientam para a produção agroecológica, coletiva e diversificada; o Estado e seus representantes apoiam e investem no agronegócio.

Entre os interesses dos organismos internacionais sobre a produção rural, Dias (2004, p. 7) analisa a ligação do Banco Mundial e o Estado na defesa da agricultura familiar:

Para o Banco Mundial, ao lançar uma proposta para a agricultura familiar brasileira, estava em questão [...] a inserção das economias nacionais no processo de globalização financeira. Neste quadro, na opinião do Banco, para o governo brasileiro restava a opção de olhar para os excluídos do processo de modernização agrícola dos anos 70, atribuindo a uma parte deste contingente um novo papel no processo de promoção do desenvolvimento. [Assim] o Banco Mundial enaltece o papel a ser assumido pelas pequenas propriedades rurais de base familiar, identificando-as como unidades de produção mais eficientes no uso dos recursos locais escassos e criadoras de um número mais significativo de empregos quando comparadas com as 'grandes propriedades corporativas' (DIAS, 2004, p. 7).

À medida que os técnicos, embora a serviço do Estado, sejam capazes de realizar um trabalho voltado aos interesses sociais dos sujeitos com os quais se comprometem, seu trabalho assume uma característica social emancipatória.

\section{O trabalho e as ações realizadas pelos técnicos: um breve histórico dos assentamentos}

A partir de dezembro de 2008, em uma ação do Ministério do Desenvolvimento Agrário (MDA) e a Superintendência Regional do INCRA no Rio Grande do Sul, foi realizada a instalação de quinhentas e noventa famílias sem-terra em cinco novos assentamentos nos municípios de São Gabriel e Santa Margarida do Sul. Convém destacar com Leite et al. (2004) que a expressão assentamento engloba uma importante diversidade de situações com origens e características que variam de acordo com o contexto histórico em que se inserem essas unidades de produção. Também são bastante diversificados os beneficiários diretos dos assentamentos de reforma agrária. 
No local em estudo, com o passar do tempo, o número de famílias assentadas aumentou, e hoje (2011) são onze áreas de assentamento neste espaço territorial. As famílias que ali chegaram provinham de várias regiões diferentes do Estado e tinham em comum o interesse de chegar à terra conquistada depois de grande período sob barracas de lona preta. Cada uma das famílias tratou de ali semear seus sonhos e planos para a constituição e concretização de uma vida digna e sustentável.

Com as famílias, chega também a oportunidade de maior desenvolvimento para os municípios e também a necessidade de obras de infraestrutura, como a abertura de estradas e a garantia de água para os agricultores, além do acesso à luz elétrica, atendimento à saúde, saneamento básico e o direito à educação; e é sobre este direito que está sendo negado que os técnicos da área social têm realizado denúncias, reflexões, estudos e lutas para a sua concretização.

A situação em que se encontram as famílias (crianças, jovens e adultos) nas áreas de assentamento de São Gabriel e Santa Margarida do Sul, após quatro anos de assentamento na região, é extremamente difícil. Esta questão é mais séria ainda quando diz respeito à educação, porque não se dá o direito de tê-la. A legislação brasileira prevê o direito à educação; assim, na Constituição Federal consta o seguinte:

Art. 205. A educação, direito de todos e dever do Estado e da família, será promovida e incentivada com a colaboração da sociedade, visando ao pleno desenvolvimento da pessoa, seu preparo para o exercício da cidadania e sua qualificação para o trabalho (BRASIL, 2001).

As leis são direitos sociais conquistados com muita persistência e luta, por isso são grandes as inquietudes e insatisfações quando se depara com a realidade dos Municípios de São Gabriel e Santa Margarida: o número de crianças matriculadas e de crianças fora da escola, o calendário escolar, a situação do deslocamento para ir a escola, o avanço na concretização do projeto da escola pólo, a desconsideração com a educação do campo, com a pedagogia da terra em relação aos professores, a proposta pedagógica das escolas que atendem às crianças dos assentamentos bem como a falta de turmas de ensino médio e profissionalizante (COOPTEC, 2011).

A legislação brasileira reformulou as regras para a educação a partir da promulgação da Lei de Diretrizes e Bases da Educação Nacional - LDB n ${ }^{\circ}$ 9.394/96 - em um contexto de privatização e redução do papel do Estado. Este processo ignorou a trajetória de reflexão e discussão da própria área de educação, representada por suas entidades, consolidando um projeto educacional de cunho neoliberal, cujo modelo se desobriga de sua responsabilidade histórica com a educação de seus cidadãos, atendendo aos ditames dos organismos internacionais. 
É o que pode ser observado neste momento nos locais em estudo. Atualmente são duzentas e três crianças matriculadas, embora o censo escolar da cidade não deixe claro o número real do aumento em razão dos assentamentos. $\mathrm{O}$ relato da diretora da Escola Municipal Ataliba Chagas de São Gabriel - que está tentando articular o processo de municipalização - mostra a diferença considerável do número de matrículas com a chegada dos assentados: "antes de dezembro havia na escola dez crianças matriculadas, hoje são em torno de 190 crianças que frequentam o Ensino Fundamental nesta escola, resultado dos assentamentos" (afirmação da Diretora).

Nessa escola, as turmas são constituídas de quinze a trinta crianças, em espaços apertados de três, no máximo, quatro metros de largura, cuja altura também é mínima, já que os alunos ficam amontoados e apresentam dificuldade até para irem ao banheiro; apenas foi feito "um puxado" onde funciona mais uma sala de aula. A escola só possui um banheiro que é utilizado por todos, o que, segundo as próprias crianças, gera vários constrangimentos. A afirmação de todos os técnicos sociais é de que, apesar do aumento do número de alunos no município, não foi realizada nenhuma melhoria significativa com relação às áreas físicas das escolas que atendem aos alunos dos assentamentos (COOPTEC, 2011).

Outra questão preocupante que compromete a qualidade de ensino nesta escola é o funcionamento do calendário escolar. Os técnicos, em suas manifestações, defendem que um dos aspectos mais importantes para a preservação das singularidades da escola do campo é a necessidade de um calendário específico. Assim, evidencia-se como as estruturas escolares não consideram a realidade dos alunos oriundos do campo que, em épocas de safra, evadem-se e perdem a continuidade dos estudos, pois o trabalho familiar necessita do seu envolvimento direto ou indireto.

Os tempos camponeses não são os mesmos dos tempos urbanos; no entanto, a existência de escolas com calendários específicos é praticamente nula, evidenciando uma total despreocupação do Estado com a frequência e o aproveitamento escolar desses alunos. Dessa forma, o que ocorre é a repetição mecânica do calendário da "rede urbana" de ensino para as escolas da área rural. Entende-se que seria desnecessário repetir que é imperativo refletir sobre a questão educativa e realizar ações para se postular uma organização do trabalho pedagógico de acordo com as necessidades da educação do campo.

Nesse caso específico, a escola atende a grupos em dias alternados, sendo três vezes na semana em turno integral às séries iniciais; nos outros três dias, às séries finais do ensino fundamental. A problemática aqui evidenciada se refere ao fato de que uma grande parte dos alunos têm aulas todos os sábados, e muitas crianças faltam às aulas neste dia para ajudar nos afazeres domésticos. A educação, nesta perspectiva, não cumpre o papel social que lhe cabe, não 
se faz presente no contexto vivido, uma vez que ignora as peculiaridades dos educandos e de suas famílias, além de não contribuir com a emancipação das massas, como afirma Freire:

A educação das massas se faz, assim, algo de absolutamente fundamental entre nós. Educação que, desvestida da roupagem alienada e alienante, seja uma força de mudança e de libertação. A opção, por isso, teria de ser também, entre uma "educação" para a "domesticação", para a alienação, e uma educação para a liberdade. "Educação" para o homem-objeto ou educação para o homem-sujeito. (FREIRE, 1967, p. 36).

Ainda sobre o calendário escolar, não há nenhuma escola (municipal ou estadual) nos dois municípios que tenha calendário diferenciado que atendam às especificidades do campo, nem mesmo adaptações nos períodos de grandes precipitações pluviométricas e/ou de dificuldades geográficas e físicas de deslocamento dos educandos. As crianças acordam muito cedo, caminham vários quilômetros e, em alguns casos, passam o dia todo na escola; ao retornarem, repetem o mesmo itinerário cansativo e massacrante.

Uma das maiores reivindicações dos pais, familias do assentamento e do próprio Movimento dos Trabalhadores Rurais Sem-Terra na região é a entrada dos ônibus escolares nos assentamentos; os municípios, por sua vez, remetem esta responsabilidade ao INCRA o qual afirma que precisa do apoio dos municípios. Dessa forma, os técnicos lançaram mais este desafio para que ocorra o apoio efetivo do Estado e colocaram esta questão em pauta durante a apresentação das reivindicações dos assentados às autoridades imbuídas de poder decisório.

Essas dificuldades acabaram provocando inúmeras evasões que já puderam ser comprovadas pelo número de matrículas no ano de 2010. Muitas crianças evadiram-se da escola devido à dificuldade de deslocamento até o ponto de ônibus, o que poderia ser resolvido se houvesse vontade política, com a união e o apoio dos poderes municipais, estaduais e também o federal. O Regime de Colaboração entre os Entes Federados (LDB N 9394/96) deixa clara esta questão. A LDB estabelece ainda que a União, em colaboração com estados, o Distrito Federal e os municípios, definirá padrão mínimo de oportunidades educacionais para o ensino fundamental, baseado no cálculo do custo mínimo por aluno, buscando assegurar um ensino de qualidade (art. 74). Além disso, de acordo com o previsto na legislação, as ações supletivas e redistribuitivas da União buscarão corrigir, progressivamente, as disparidades de acesso e garantir o padrão mínimo de qualidade de ensino (art. 75).

Especificamente sobre o regime de colaboração entre os entes federativos para o desenvolvimento da educação do campo, o Decreto Presidencial ${ }^{\circ}$ 7352/2010 assegura: 
Art. $1^{\circ}$ A política de educação do campo destina-se à ampliação e qualificação da oferta de educação básica e superior às populações do campo e será desenvolvida pela União em regime de colaboração com os Estados, o Distrito Federal e os Municípios, de acordo com as diretrizes e metas estabelecidas no Plano Nacional de Educação e o disposto neste Decreto.

Pode-se comprovar que a educação e a possibilidade de emancipação dos grupos sociais são negadas nos municípios de Santa Margarida do Sul e São Gabriel. Como refere Freire (1967, p. 26), se a humanização dos oprimidos é subversão, sua liberdade também o é; daí a necessidade de seu constante controle. $\mathrm{E}$, quanto mais controlam os oprimidos, mais os transformam em "coisa", em algo que é como se fosse inanimado. Essa afirmação de Freire é fundamental para o entendimento das relações entre opressor e oprimido, pois, na "imersão" em que se pretende colocar os sujeitos, não podem discernir, claramente, na condição de oprimidos, os interesses dos opressores.

Nesta perspectiva, acaba sendo negada a possibilidade de o próprio grupo de assentados se constituírem enquanto classe, ao mesmo tempo em que não se permite que a educação popular no e do campo aconteça no assentamento - ao não dialogar com o povo que reivindica a construção de escolas em seus assentamentos. Esse é o caso de Santa Margarida do Sul onde a atual Prefeita afirma não haver neste local necessidade de uma escola. Desta forma, o poder público impede que o conhecimento historicamente construído seja socializado pelos sujeitos envolvidos. De acordo com Freire (1967, p. 43),

[...] toda vez que se suprime a liberdade, fica ele um ser meramente ajustado ou acomodado. E é por isso que, minimizado e cerceado, acomodado a ajustamentos que lhe sejam impostos, sem o direito de discuti-los, o homem sacrifica imediatamente a sua capacidade criadora.

Quando não possibilita ou concretiza a matrícula das crianças, ou não cria condições para que permaneçam na escola, dificulta a situação dos educandos e das famílias. Sobre isso foram coletadas as informações ${ }^{5}$ in loco e enviados os dados à Secretaria Municipal de Educação de que são trinta e duas crianças que estão fora da escola no Assentamento Caiboaté e que quatro delas não possuem nem matrícula. No Assentamento Itaguaçu, por sua vez, são dez crianças fora da escola, mais trinta que estão na Fazenda $33^{6}$, sendo que esta última não faz parte da rota do ônibus escolar. Em alguns casos houve dificuldade de encontrar as crianças e suas famílias que podem estar isoladas e sem atendimento, significando que não se tem levantamento exato do número de crianças fora da escola nos assentamentos dos municípios em pauta. Este fato foi levado ao conhecimento

\footnotetext{
${ }^{5}$ Relatório (2010) entregue à COPTEC pelos Técnicos da ATES.

${ }^{6}$ Caiboaté, Itaguaçu e Fazenda 33 são assentamentos localizados no município de São Gabriel.
} 
do Conselho Tutelar do Município pelos técnicos, ocasião em que solicitaram que o Ministério Público fosse também comunicado.

Por outro lado, enquanto a situação das crianças e dos adolescentes destes locais, no que se refere à educação, é de total exclusão, o Decreto Presidencial N ${ }^{\circ}$ 7.352, de 4 de novembro de 2010, em seu Artigo $1^{\circ} \int 4^{\circ}$ assegura que:

A educação do campo concretizar-se-á mediante [...] a garantia de condições de infra-estrutura e transporte escolar, bem como de materiais e livros didáticos, equipamentos, laboratórios, biblioteca e áreas de lazer e desporto adequados ao projeto político-pedagógico e em conformidade com a realidade local e a diversidade das populações do campo.

A legislação, entretanto, ao mesmo tempo em que assegura o direito destes educandos, não garante que os governantes efetivamente coloquem em prática os dispositivos legais. Com isto, embora de direito, a questão educacional deste grupo pareça resolvido, de fato, nada acontece.

Uma das alternativas para melhorar estas condições seria a concretização do projeto de construção da Escola Polo - Projeto do Ministério do Desenvolvimento Agrário (MDA) e MEC - para as escolas em zona rural, para atender à demanda da Educação nas áreas de Assentamento. Neste caso, São Gabriel deveria encaminhar o projeto ao MEC. O INCRA fez a doação oficial de um terreno de treze hectares localizado na área de Assentamento Itaguaçu para a construção da escola. A informação do município é que já encaminhou o projeto, mas que ele estaria "parado" no MEC. Procurou-se em vão ter acesso ao projeto, pois a Secretaria de Educação e Cultura do Município apresenta apenas informações desencontradas. Já na Coordenadoria de Educação, a informação dada é semelhante, ou seja, não há definição.

Esta reivindicação da construção da escola Polo dentro da área de Assentamento, para as famílias e também para o MST, representa a concretização de uma escola formadora de sujeitos articulada a um projeto de emancipação humana: com princípio pedagógico da valorização dos diferentes saberes no processo educativo; o princípio pedagógico dos espaços e dos tempos de formação dos sujeitos da aprendizagem; o princípio pedagógico do lugar da escola vinculado à realidade dos sujeitos; o princípio pedagógico da educação como estratégia para o desenvolvimento sustentável; e o princípio pedagógico da autonomia e colaboração entre os sujeitos do campo e o sistema nacional de ensino.

Nesta perspectiva, entende-se que a educação estaria cumprindo com seu papel social e criando, assim como assinala Freire (1967, p. 45), a necessidade de uma permanente atitude crítica, único modo pelo qual o homem realizará sua vocação natural de se integrar, superando a atitude do simples ajustamento ou acomodação. Desta forma, corroborando com Freire, entende-se que a 
importância do comprometimento, da valorização dos conhecimentos de mundo que os alunos já possuem e a apropriação do conhecimento novo conduz à autonomia e representa um instrumento de libertação para os oprimidos.

Essas são características da educação popular voltada ao homem do campo que, de acordo com Brandão (1985), pode ser compreendida como educação das classes populares, como saber da comunidade/conhecimento popular e como ensino público. Se a educação do homem do campo é compreendida como uma das concepções de desenvolvimento das classes populares, ela encontra respaldo em Paulo Freire, especialmente quando se concorda com a afirmação de Mançano (2000, p. 92) de que:

O Campo é lugar de vida, onde as pessoas podem morar, trabalhar, estudar com dignidade de quem tem o seu lugar, a sua identidade cultural. O campo não é só lugar da produção agropecuária e agroindustrial, do latifúndio, de grilagem de terras. O campo é espaço e território dos camponeses e dos quilombolas. É no campo que estão as florestas, onde vivem as diversas nações indígenas. Por isso tudo o campo é lugar de vida e, sobretudo, de educação.

Exatamente esses foram alguns dos argumentos levantados pelo grupo de técnicos e encaminhado à SECADI/MEC/CGEC, coordenação responsável pela Educação do Campo, de quem receberam a confirmação de que, no início do ano de 2012, o local seria visitado pela Coordenação da Educação do Campo, com vistas à busca de alternativas e soluções.

As questões inerentes à realidade do campo, portanto, precisam ser consideradas, pois quando se definem as políticas locais, as macropolíticas precisam se ancorar nos saberes dos educandos e na temporalidade, no sentido de compreender e contribuir com o desenvolvimento social dos sujeitos que vivem nesse espaço e nele se constituem como cidadãos.

\section{O caráter político e emancipatório da proposta freireana nos espaços educativos não-formais}

A expressão "espaço não-formal” tem sido empregada por pesquisadores em Educação, professores de diversas áreas do conhecimento e profissionais de outras áreas para descrever lugares diferentes da escola nos quais é possível desenvolver processos e ações educativas. Em relação aos movimentos sociais, a própria Lei de Diretrizes e Bases da Educação Nacional nº 9394/96 apresenta-os como espaços e processos educativos:

Art. $1^{\circ}$. A educação abrange os processos formativos que se desenvolvem na vida familiar, na convivência humana, no trabalho, nas instituições de ensino e pesquisa, nos movimentos sociais e organizações da sociedade civil e nas manifestações culturais. (BRASIL, 1996). 
Assim, os próprios movimentos sociais ou o trabalho educativo e politizante dos técnicos sociais contribuem com a educação através de espaços de educação não-formal, com a formação cidadã, e permitem a inserção dos sujeitos e de suas ideias no conjunto mais amplo da sociedade, pois, assim como afirma Gohn (2009), na educação não-formal, o grande educador é o "outro", aquele com quem se interage ou com quem se integra.

Paulo Freire $(1967,1985,2000)$ contribuiu para o entendimento da relação entre movimentos sociais e educação popular. Essa contribuição aparece na construção de sua reflexão em torno do processo de produção do ser humano como sujeito, da potencialidade educativa da condição de oprimido, bem como do esforço para tentar deixar de sê-lo, o que quer dizer: lutar para transformar a realidade social. Fiori (apud FREIRE, 1985, p. 8) afirma que "Paulo Freire reproduz em plano próprio a estrutura dinâmica e o método dialético do processo histórico de produção do homem".

Ao defender a educação popular como "Educação libertadora", como "Educação como prática da liberdade", Freire afirma que ela, embora esteja sustentada em grandes lineamentos, se faz e refaz continuamente na experiência dos indivíduos e coletivos que a fazem. Está, portanto, em constante movimento e busca a transformação total da sociedade.

Os movimentos sociais populares são movimentos que educam de forma específica porque têm em comum o sentido político da educação. O caráter educativo manifesto nestas experiências, como espaço das práticas sociais, coloca-as como lugares adequados ao desenvolvimento de uma educação crítica e emancipatória. Freire (1996, p. 28) assegura, na obra "Pedagogia da Autonomia", que

Em nome do respeito que devo aos alunos não tenho por que me omitir, por que ocultar a minha opção política, assumindo uma neutralidade que não existe. Esta, a omissão do professor em nome do respeito ao aluno, talvez seja a melhor maneira de desrespeitá-lo. O meu papel, ao contrário, é o de quem testemunha o direito de comparar, de escolher, de romper, de decidir e estimular a assunção deste direito por parte dos educandos.

Neste sentido, a ação do todo o educador em caráter formal e não-formal é uma ação social e não pode ser considerada neutra, visto que, na correlação de forças entre seu agir e as demandas que emergem do contexto em que atua, situam-se marcos que definirão sua opção, a favor do oprimido ou do opressor. A questão da neutralidade também é discutida por Freire (1996, p. 70), quando indaga "Que é mesmo a minha neutralidade senão a maneira cômoda, talvez, mas hipócrita, de esconder minha opção ou meu medo de acusar a injustiça?", ou seja, o silenciamento frente às atitudes e ações opressoras constitui-se numa aceitação passiva da própria opressão, ainda mais quando serve ao interesse de fortalecimento do "discurso opressor hegemônico". 
Por esta razão, afirma-se que os sujeitos sociais, técnicos sociais, na condição de realização e de participação em movimentos sociais de caráter popular educativo, têm tentado cumprir com seu compromisso social, pelas várias ações realizadas neste espaço em estudo, inclusive ao procurarem os meios de comunicação para fazerem denúncias, embora pareça não haver "interesse" em divulgar tais fatos.

Além dessas ações, os técnicos realizaram atos educativos junto ao grupo de educandos, trabalhando com oficinas nas áreas de assentamento, mesmo nos locais em que não existem escolas. Nessas oficinas (muitas realizadas embaixo das lonas pretas, ou sob as árvores, ou em uma casa antiga que era a casa-sede da fazenda adquirida pelo INCRA, na qual estão alguns dos assentados e que atualmente está totalmente deteriorada), os estudos envolveram conscientização da preservação ambiental, da importância da agricultura familiar sustentável, além da discussão de propostas de saneamento, hábitos alimentares, higiene pessoal e perigos com a utilização de agrotóxicos.

Esclareceram sobre a necessidade de entender a conjuntura presente que atribui valores aos transgênicos em detrimento à produção orgânica, o que, segundo Andrioli (2006), é responsabilidade da grande mídia, que propaga os maiores argumentos favoráveis à expansão de transgênicos em todo o mundo (a experiência com a soja transgênica tem demonstrado claramente que, ao invés de solucionar questões da agricultura, a transgenia vem provocando novos problemas técnicos). Assim, o processo educativo desenvolvido em espaços educativos formais ou não-formais tem o compromisso de alertar sobre estas e outras questões, que são ofuscadas pelos discursos oficiais e pela mídia.

Deste modo, os discursos educacionais ou suas práticas estão imbricados em uma série de contextos e de circunstâncias que podem ser confirmados ou confrontados no espaço educativo onde são colocados em prática.

\section{Considerações finais}

A promulgação da Constituição Brasileira de 1988 representou um marco na relação entre Estado e Movimentos Sociais, especialmente em razão da possibilidade da ocupação de espaços nos organismos estatais, propondo políticas, programas e ações concretas voltadas para a satisfação de seus interesses e exigindo a sua execução na forma de políticas públicas.

O Brasil, a partir desse período, passou a ser um país respeitado na luta pelos direitos humanos, tornando-se inclusive uma referência para outros países no que diz respeito às ações de caráter afirmativo e nos tratados e nas convenções internacionais que regulam os direitos fundamentais da pessoa. 
As contradições a essas determinações, no entanto, são evidentes. Um exemplo concreto está na ação do poder público nos municípios de Santa Margarida e São Gabriel no Rio Grande do Sul, pois o que se vê é a omissão dos poderes (Executivo, Legislativo e Judiciário) o que viola sistematicamente os direitos humanos. Isto evidencia um Estado que se omite e não contribui com os movimentos populares que lutam pelo cumprimento dos direitos básicos renegados por ele próprio, reivindicando uma justiça social mais ampla.

Diante dessa realidade, por iniciativa dos sujeitos envolvidos nos movimentos sociais, trabalhadores e técnicos sociais, estão sendo realizadas atividades que buscam colocar a sociedade a par do que acontece com o objetivo de mostrar a responsabilidade do poder Executivo. Esses sujeitos sociais entendem que "não é no silêncio que os homens se fazem, mas na palavra, no trabalho, na ação-reflexão" (FREIRE, 2003, p. 92).

Os trabalhadores da área social procuram se organizar e divulgar suas reivindicações, fato que contribui para a politização, não apenas dos seus componentes e simpatizantes, mas da sociedade como um todo. Assim como assegura Dias (2004, p. 39):

A proposta do serviço de ATES é extremamente positiva e oportuna. Surgiu em um momento histórico, no qual foram construídas enormes expectativas sobre a ampliação e qualificação dos processos de reforma agrária. Suas boas intenções fazem uma importante leitura, embora pouco sistemática, de algumas concepções críticas que revisam os modos predominantes de exercício da prática extensionista, questionando o domínio do caráter assistencial e técnico que a caracterizou ao longo do processo de modernização da agricultura.

Isto leva à afirmação de que, enquanto avançam em suas lutas, contribuem para a politização e conscientização das camadas populares confirmando a relação dialética existente entre os movimentos sociais, o Estado e a classe dominante. Neste prisma, suas ações são educativas e têm um caráter popular, assim como várias outras iniciativas populares semelhantes, com um caráter crítico, didático e conscientizador.

A luta desse movimento realizada pelos técnicos sociais, bem como a desenvolvida pelos demais movimentos sociais, de caráter popular do campo, buscam defender a educação básica do campo, como aquela

[...] voltada ao interesse do campo, voltada ao interesse e ao desenvolvimento sociocultural e econômico dos povos que habitam e trabalham no campo, atendendo às suas diferenças históricas e culturais para que vivam com dignidade e para que, organizados, resistam contra a exploração e a expropriação, ou seja, este do campo tem o sentido do pluralismo das ideias e das concepções pedagógicas: diz respeito à identidade dos grupos formadores da 
sociedade brasileira (conforme os artigos 206 e 216 da nossa Constituição) [...]. (KOLLING; NERY; MOLINA, 1999, p. 28-29).

Constitui-se, nessas lutas, um novo sujeito (coletivo), numa prática nova e numa nova postura, o que na realidade em pauta se configura na pessoa dos técnicos. Ao fazer-se sujeito político no ato da criação de espaços de experiência (DOIMO, 1995), portanto, educadores sociais, juntos aos movimentos, estabelecem-nos como sujeitos e como cidadãos. Neste sentido, não se coloca a constituição de sujeitos coletivos através de identidades que lhes foram atribuídas, mas as que a própria ação e os sujeitos envolvidos ou o próprio movimento como sujeito se atribui.

\section{Referências}

AGÊNCIA BRASIL. Folha online: Lula pede agilidade na liberação de recursos para agronegócio. Disponível em: <http://www1.folha.uol.com.br/folha/dinheiro/ ult91u552250.shtml>. Acesso em: 19 out. 2009.

ANDRIOLI, A. I.; FUCHS, R. (Orgs.). Transgênicos: as sementes do mal. A silenciosa contaminação de solos e alimentos. Lahnstein: Editora Emu, 2006.

ARROYO, M.; FERNANDES, B. M. A educação básica e o movimento social do campo. Brasília: Articulação Nacional por uma educação, 2000. (Coleção Por uma educação básica do campo, n. 2).

BRANDÃO, C. R. Educação Popular. São Paulo: Brasiliense, 1985.

BRASIL. Constituição da República Federativa do Brasil - 1988. São Paulo: Forense, 5. ed. 2001.

. Lei no. 9394/96 de 20 de dezembro de 1996. Estabelece as diretrizes e bases da educação nacional. Diário Oficial da União, Brasília, 23 dez. 1996. Disponível em: <http:// portal.mec.gov.br/arquivos/pdf/ldben.pdf>. Acesso em: $1^{\circ}$ ago. 2007.

Decreto Presidencial $\mathrm{n}^{\mathrm{o}}$ 7.352, de 4 de novembro de 2010. Dispõe sobre a política de educação do campo e o Programa Nacional de Educação na Reforma Agrária PRONERA. Disponível em: <http://www.planalto.gov.br/ccivil_03/_Ato2007-2010/2010/ Decreto/D7352.htm>. Acesso em: 13 jan. 2011.

. Dados do Censo 2011. Disponível em: <http://www.ibge.gov.br/home>. Acesso em: 24 fev. 2012.

CASTORIADIS, C. Socialismo ou barbárie: o conteúdo do socialismo. Coord. Marilena Chauí. São Paulo: Brasiliense, 1983. (Coleção A invenção democrática).

COOPTEC. Relatório de Atividades da ATES. Equipe Social Situação Educacional das Crianças, Jovens e Adultos, Núcleo Operacional São Gabriel, 2011.

DIAS, M. M. Extensão rural para agricultores assentados: uma análise das boas intenções propostas pelo "Serviço de ATES" Cadernos de Ciência e Tecnologia, Brasília, v. 21, n. 3, p. 499-543, set./dez. 2004. 
DOIMO, A. M. A vez e a voz do popular: movimentos sociais e participação política no Brasil Pós-70. Rio de Janeiro: Relume -Dumará: ANPOCS, 1995.

FREIRE, P. Educação como prática de liberdade. São Paulo: Paz e Terra, 1967.

A Pedagogia do Oprimido. 14. ed. São Paulo: Paz e Terra, 1985.

Pedagogia da autonomia: saberes necessários à prática educativa. São Paulo: Paz e Terra, 1996 (Coleção Leitura).

GOHN, M. da G. Teorias dos Movimentos Sociais: paradigmas clássicos e contemporâneos. São Paulo: Loyola, 2000.

Movimentos Sociais e Educação. São Paulo: Cortez. 2009.

GRAMSCI, A. Os intelectuais e a organização da cultura. Tradução de Carlos Nelson Coutinho. 2. ed. Rio de Janeiro: Civilização Brasileira, 1978.

INCRA. Instituto Nacional de Colonização e Reforma Agrária. Assessoria Técnica, Social e Ambiental à Reforma Agrária (ATES): diretrizes e manual operacional. Brasília, 2004.

KOLLING, E. J.; NERY, I. J.; MOLINA, M. C. (Orgs.). A Educação Básica e o movimento social do campo. Brasília: UnB, 1999. (Coleção Por uma educação básica do campo, n. 1).

KONRAD, D. História do presente e a atualidade de "O Dezoito Brumário de Luiz Bonaparte” de Karl Marx. s. d. Disponível em: <http://www.unicamp.br/cemarx/diorge. htm>. Acesso em: 18 ago. 2011.

LESSA, S. Trabalho e proletariado no capitalismo contemporâneo. São Paulo: Cortez, 2007.

MARX, K. O Capital. São Paulo: Ed. Civilização Brasileira, 2011. Livro 1, v. 1.

Contribuição à crítica da economia política. São Paulo: Expressão Popular, 2008.

O 18 brumário e cartas a Kugelmann. 2. ed. Rio de Janeiro: Paz e Terra, 1974.

MARX, K.; ENGELS, F. A ideologia alemã. São Paulo: Martins Fontes, 2007.

LEITE, S. et al. Impactos dos assentamentos: um estudo sobre o meio rural brasileiro. Brasília: Instituto Interamericano de Cooperação para a Agricultura - Núcleo de Estudos Agrários e Desenvolvimento Rural. São Paulo: Editora UNESP, 2004. (Estudos NEAD, 6).

MEDEIROS, L. S. "Sem terra", "assentados", "agricultores familiares": considerações sobre os conflitos sociais e as formas de organização dos trabalhadores rurais brasileiros. In: CONGRESSO BRASILEIRO DE SOCIOLOGIA, 9., 1999, Porto Alegre. Anais... Porto Alegre: SBS, 1999. 1 CD-ROM.

JORNAL DO MST, 2009. Disponível em: < http://www.mst.org.br/node/6513.>. Acesso em: 23 mar. 2011.

TRIVIÑOS, A. N. S. Introdução à pesquisa em ciências sociais: a pesquisa qualitativa em educação. São Paulo: Atlas, 1987.

Recebido em 20/11/2011

Versão final recebida em 19/02/2012

Aceito em 17/03/2012 